\section{Drug and cigarette company donations} favour Republicans

Washington. With Republicans seeking to relax regulations on US drug companies - and the Clinton administration to extend controls over tobacco companies - the industries have responded by donating more than three times as much to the Republican Party as to the Democrats in the 18 months that ended in June.

A new study by Common Cause, a Washington group that lobbies for campaign finance reform, shows the Republican Party received $\$ 7.1$ million from tobacco and drug companies between January 1995 and June 1996. The Democratic Party received $\$ 2.0$ million - or 28 per cent of the Republican figure.

The figures were compiled from reports that have to be filed with the Federal Election Commission. The reports also show that tobacco companies in particular leaned towards the Republicans, donating $\$ 4$ million, compared to the $\$ 746,000$ they gave to the Democrats.

The donations to the two main US political parties - often referred to as "soft money" - provide a way by which corporate donors and wealthy individuals can by-pass stringent legal limits on campaign contributions. There are no limits on the size of such donations, provided that they help the party generally and no candidate specifically.

Pharmaceutical and tobacco companies in particular have grasped the opportunity to use soft money to court the Republican Party, which took over the US Congress in January last year for the first time in 40 years. For both industries, "Republicans are generally much more sympathetic to their point of view," says Larry Sabato, a professor of government at the University of Virginia, and co-author of a new book on campaign finance.

And Republicans have not been unresponsive. They have pleased pharmaceutical companies by pushing to amend laws governing the Food and Drug Administration (FDA). Proposed changes would shorten approval times for drugs and medical devices, and relax testing requirements by allowing fewer clinical trials and less data collection by companies.

Tobacco companies, meanwhile, have sought Republican help in fighting what they call an anti-smoking onslaught by the FDA. President Bill Clinton announced last month, for example, that the FDA is to regulate nicotine as an addictive drug, and cigarettes as drug delivery devices. $\mathrm{He}$ launched strict new controls on tobacco companies' advertising to children. Meredith Wadman

\title{
Scientists split over tobacco industry research funding
}

London. Sir Richard Doll, the epidemiologist who first established the link between smoking and lung cancer, last week said he saw "no harm" in tobacco companies funding biomedical research, providing scientists retain "total control" over the use of the funds and the right to publish the research.

Doll was responding to the debate ignited by reports of a decision by the Medical Research Council (MRC) to accept a grant of $£ 147,000$ (US $\$ 225,000$ ) from BAT Industries, owners of British American Tobacco. The money is being spent on a three-year study into whether nicotine is of potential benefit to sufferers of Alzheimer's disease.

The MRC's decision has been greeted with astonishment by cancer research charities such as the Imperial Cancer Research Fund, as well as anti-smoking organizations. The outcry has led to an admission from the scientist who accepted the funds that he would not do it again, to spare the MRC the bad publicity. It has also resulted in the temporary suspension of Mary Rice, the MRC's head of public communication, who voiced misgivings in a newspaper interview.

Doll, who is now with the Imperial Cancer Research Fund Cancer Studies Unit at the University of Oxford, describes the reaction as unwarranted. $\mathrm{He}$ adds that he has sometimes found industrial sponsors more willing to allow him to retain the right to publish research than government departments, such as the Department of Health, "who have tried to lay down conditions".

Despite the misgivings of both its public affairs manager and Jim Edwardson, director of its Neurochemical Pathology Unit in Newcastle, the MRC stands by its decision to accept the tobacco company funds.

According to a spokeswoman, BAT has also paid $£ 60,000$ for two $\mathrm{PhD}$ students at the MRC Toxicology unit at the University of Leicester. Their three-year grant was used for research into the damage to chromosomes caused by a number of chemicals including nitrosodiethylamine, which is found in trace quantities in tobacco smoke.

Jane Lee, the MRC's director of corporate affairs, acknowledges that the question of accepting research funding from tobacco companies is a "grey area" and the subject of debate within the council. But, she adds, a blacklist of unacceptable companies might pose a further dilemma, as other non-tobacco companies engaged in controversial commercial activities would need to be included.

Lee also points out that the conditions attached to the BAT funding are tighter than for some non-tobacco sources. "BAT is not allowed to publicize this research in any way, or use it in promotional activities, without the MRC's permission."

The tobacco industry pays $£ 9$ billion a year in taxes. Lewis Smith, director of the MRC's Toxicology Unit, says that if people are "willing to go into a hospital paid for by BAT taxes", he sees no reason why researchers should not use the same source of funds, providing they do not endorse smoking or promote the tobacco company.

But the critics are far from satisfied. Margaret Wilson, head of public relations at the Imperial Cancer Research Fund (ICRF), says the fund was "surprised and disappointed" that the MRC had accepted funds from BAT. Karen Williams, a spokeswoman for the pressure group, Action on Smoking and Health, finds the idea "abhorrent".

The ICRF collaborates with industry, but would find it "unthinkable" to take money from tobacco companies "which are responsible for a third of all cancer deaths", says Wilson. Williams questions BAT's motives for giving the money. "There must be something in it for the tobacco industry. The MRC is naive to think there isn't."

Both Williams and Wilson argue that, while research into the effects of nicotine is essential, it should be funded from outside the tobacco industry. They believe that, despite the MRC's 'watertight' conditions, BAT will benefit more from its sponsorship now that the issue has been made public especially if the research shows nicotine is potentially useful for Alzheimer's sufferers.

Williams says it is "unacceptable" for an industry that is responsible for the hundreds of millions of pounds spent each year fighting nicotine-related cancer to be allowed to benefit from the acclaim that would accompany any positive finding relating to nicotine.

But a spokesman for BAT, which spends $£ 500,000$ each year on medical research, says research is funded "out of a sense of corporate responsibility", and not to obtain publicity, which is why the identity of the recipients is not made public.

He says the funds are allocated by a panel of independent scientists. The research results are "always peer-reviewed and published", but a decision to acknowledge the source of funds remains with the scientists. Similarly the company cannot use any of the results without the scientists' permission.

One former member of the MRC's governing council suggests that conglomerates that contain tobacco interests ought to give money into a central 'pool' of funds that is administered independently. This ought to satisfy the critics and establish the sincerity of the tobacco companies' motives, he says. The BAT spokesman says the idea of pooling funds is "an interesting suggestion worth considering".

Ehsan Masood 